\title{
Flipped learning design fidelity, self-regulated learning, satisfaction, and continuance intention in a university flipped learning course
}

\author{
Nam Hui Kim \\ Korea Research Institute for Vocational Education \& Training \\ Hyo-Jeong So, Young Ju Joo \\ Ewha Womans University, Korea
}

For effective flipped learning, beyond simply switching the sequence of lectures and homework, it is important to understand and implement the fundamental design principles of flipped learning. A new notion is proposed called flipped learning design fidelity, defined as the degree to which a class is faithfully designed to be close to an ideal flipped learning class operationalised with four proxy indicators of the F-L-I-PTM model (flexible environment, learning culture, intentional content, and professional educator). This study empirically examines the effect of both learner-related factor (self-regulated learning) and design-related factor (design fidelity) on learning outcomes (satisfaction, continuance intention) in a university flipped course. We hypothesised that flipped learning design fidelity and selfregulated learning affect student satisfaction and intention to continue participating in a flipped learning course. The participants were 134 Korean students of a university course taught in a flipped learning mode. The results revealed that the level of flipped learning design fidelity had a significant effect on satisfaction, but did not affect continuance intention. In addition, the level of self-regulated learning had a significant effect on satisfaction and continuance intention. Drawn from the key findings, we suggest implications for the design of flipped learning courses in a university context.

\section{Implications for practice:}

- Instructional designers and instructors can apply the concept of flipped learning design fidelity to fully implement the four pillars of the F-L-I-PTM model.

- $\quad$ Self-regulated students are likely to be satisfied with flipped learning and want to continue taking flipped learning courses.

Keywords: flipped learning, design fidelity, self-regulated learning, satisfaction, continuance intention

\section{Introduction}

To meet the demands of the twenty-first century, higher education institutions have undergone a massive transformation of teaching and learning with new approaches, systems, and structures. Flipped learning is one such a transformative attempt that higher education institutions are experimenting with, to promote learner-centered pedagogical approaches (O'Flaherty \& Phillips, 2015). In general, flipped learning means that before class, learners acquire content knowledge through video lectures and supplementary materials provided by an instructor, then in class, they expand their knowledge by participating in various activities, such as discussions and collaborative work (Bergmann \& Sams, 2012).

In the existing literature, two major aspects of the rationale for flipped learning as a learner-centered pedagogy can be identified. First, since lecture content in a flipped learning class delivered to learners in the form of video, in-class time for delivering content is significantly reduced (Brame, 2013). With fewer hours needed to cover content in the classroom, instructors have more time to apply various learning activities to further improve student understanding (Hao \& Lee, 2016; Le Roux \& Nagel, 2018). Second, flipped learning has the potential to develop higher-level cognitive competences such as complex problem solving and critical thinking skills (Hwang et al., 2015). According to Bloom's taxonomy of learning outcomes, what students do before class - watching lecture videos that deliver basic knowledge - belongs in the lower levels of cognitive learning (Bergmann \& Sams, 2014). In essence, pre-class video lectures 
function as a means of cognitively preparing students to acquire knowledge and readiness that enable them to fully engage in high-level cognitive activities in class.

In this study, we focus on the design and student-related factors in flipped learning. First, if nothing else changes, simply moving a traditional lecture from a classroom to an online platform is unlikely to generate significant and meaningful differences. While it is clear that flipped learning focuses on designing a classroom environment where learners can construct own meanings ( $\mathrm{Ng}, 2014$; Sohrabi \& Iraj, 2016), the biggest obstacle to the implementation of flipped learning has been reported as the burden on instructors to produce lecture videos in advance (Roehl et al., 2013). It is still possible that in-class teaching remains an instructor-centered approach when the instructor focuses mainly on developing the videos before class and fails to consider the instructional design of flipped learning.

Second, when students do not self-regulate their learning process to complete pre-class activities (e.g., watching lecture videos), their subsequent participation in class is less engaging and effective (Tomas et al., 2019). Previous research found that learners who are accustomed to traditional teaching and learning methods tend to have negative attitudes toward flipped learning or avoid flipped learning methods (He et al., 2016). Hence, understanding how self-regulated learning works and influences student learning outcomes, such as learner satisfaction and continuance intention, can provide important information for the field of flipped learning research and practice. With the increasing recognition of student motivation to complete pre-class activities, researchers have begun to examine the role of self-regulated learning in the flipped learning context (e.g., Lai \& Hwang, 2016; Sun et al., 2018). However, there is still a lack of empirical research conducted in a university context.

Taking a socio-cognitive view, we posit that self-regulated learning is not determined solely by learners' processes, but is significantly influenced by "environmental and behavioral events in reciprocal fashion" (Zimmerman, 1989, p.330). As a learning environmental factor, we propose the notion of flipped learning design fidelity to indicate how a flipped learning class is designed to faithfully integrate the design principles of flipped learning, which are operationally taken from the four indicators of the F-L-I-PTM model (Hamdan et al., 2013): (1) flexible environment, (2) learning culture, (3) intentional content, and (4) a professional educator. Moreover, the reciprocity of self-regulated learning strategies and the fidelity of flipped learning design is posited to influence student learning outcomes, which this study measured through student satisfaction and continuance intention with flipped learning. Although flipped learning design and self-regulated learning are key factors to consider in implementing a flipped learning class, there are still insufficient explorations as to whether flipped learning provides learners with a satisfactory level of learning experiences and influences their continuance intention to participate in flipped learning classes.

In subsequent sections, we provide the theoretical background that guided the construction of the relationship between these variables and the research study conducted with university students in Korea. Through the empirical exploration, this study aimed to provide contributions for the effective design and implementation of flipped learning courses in higher education.

\section{Theoretical background}

\section{Designing flipped learning environments}

On the surface, the design of flipped learning appears simple, that is, switching the sequence of pre-class and post-class activities. However, at a deeper level, flipped learning encompasses multiple levels of design, including lesson, course, program, and intuitional levels. In the literature, we identified the four core elements of conceptualising flipped learning: (1) time (before class, during class, after class), (2) space (inclass vs. out-of-class, online vs. offline); (3) types of activities (individual vs. group); and (4) use of technology (technology-mediated vs. face-to-face interaction). These make for complex configurations of flipped learning design.

Despite the complexity of flipped learning design, there is a lack of design guidelines that can inform careful considerations of multiple elements, beyond simply switching the sequence of lectures and homework. Lack of design guidelines and principles have been identified as one of the significant gaps in the body of flipped learning research (e.g., Brewer \& Movahedazarhouligh, 2018; Chen et al, 2014). With that, the FL-I-PTM model developed by the Flipped Learning Network (FLN) provides researchers and practitioners 
with useful frameworks and guidelines to consider multiple elements of the design of flipped learning (Hamdan et al. 2013). The F-L-I-PTM model pillars (Table 1) work as basic and unified indicators that researchers and practitioners consider in the design of flipped learning environments. Based on this model, instructors can design flipped learning courses by combining and extending what they want to emphasise (e.g., flipped project-based learning, flipped mastery, and gamification) (Bergmann \& Sams, 2014).

Table 1

The F-L-I-P $P^{\mathrm{TM}}$ model: The four pillars and indicators (Hamdan et al., 2013) Pillar Indicators

Flexible environment $\quad$ - I establish spaces and time frames that permit students to interact and reflect on their learning as needed.

- I continually observe and monitor students to make adjustments as appropriate.

- $\quad$ I provide students with different ways of learning content and demonstrating mastery.

Learning culture $\quad$ I give students opportunities to engage in meaningful activities without the teacher being central.

- I scaffold these activities, and make them accessible to all students through differentiation and feedback.

Intentional content $\quad$ - I prioritize concepts used in direct instruction for learners to access on their own.

- I create and/or curate relevant content (typically videos) for my students

- I differentiate to make content accessible and relevant to all students.

Professional educator - I make myself available to all students for individual, small group, and class feedback in real-time as needed.

- I conduct ongoing formative assessments during class time through observation, and by recording data to inform future instruction.

- I collaborate and reflect with other educators, and take responsibility for transforming my practice.

The first pillar is a flexible environment, where the instructor gives learners autonomy to participate in various learning modes (e.g., collaborative learning, individual learning, and research assignments). In addition to and unlike a traditional lecture-centered class, a flexible environment means that there should be no constraint on chaotic and noisy situations caused by collaborative activities and discussions. The flexible learning environment also includes learner flexibility in time and space. Second, flipped learning seeks to promote a learning culture that is grounded in a learner-centered pedagogy. In flipped learning, learners construct knowledge in a self-directed manner by actively participating in various activities in class, meaning that the main responsibility for learning is transferred from the instructor to the learner (Davis et al., 2013). Third, for successful flipped learning, the instructor needs to continuously consider how to develop various learning strategies and materials that can help maximise classroom time. The F-L-I-P ${ }^{\mathrm{TM}}$ model refers to this pillar as intentional content. In some cases, depending on the type of knowledge, instructors need to be careful about what content to include in pre-class videos. Finally, the F-L-I-PTM model emphasises the role of the professional educator. Social constructivism considers the instructor to be a facilitator, and learner knowledge construction is also influenced by the surrounding social networks, such as teachers and peer learners $(\mathrm{Ng}, 2014)$. Consistent with the social constructivist view, instructors in a flipped learning class should be able to continuously observe and evaluate learner activities, provide appropriate feedback, accept constructive criticism, and promote learner competence in self-regulated learning.

\section{Flipped learning design fidelity}

In this research, we expanded flipped learning by introducing the new concept called flipped learning design fidelity, which we define as the degree to which a class is faithfully designed to be close to an ideal flipped learning class operationalised using the four proxy indicators (i.e., flexible environment, learning culture, intentional content, and a professional educator) from the F-L-I-P ${ }^{\mathrm{TM}}$ model. Fidelity can be both physical and cognitive (Collins, 1996). In the industrial design field, fidelity usually means functional or physical fidelity, which indicates how similarly the prototyping is functioning to the actual product (Rudd et al., 1996). In instructional design, the concept of fidelity carries somewhat different meanings, in that it refers 
to how closely the instructional designer's intended program corresponds to the actual situation of learning or training (Spector et al., 2014). High fidelity means that the learning situation is highly similar to the actual situation in which the learner's knowledge is to be used, maximising the likelihood of a learner's success in transferring knowledge and skills (Branch, 2009; van Merriënboer \& Kester, 2008). However, it is important to note that fidelity does not necessarily mean that learning has to always deal with authentic problems and tasks. Rather, Spector et al. (2014) argue that "authenticity can best be described as the extent to which the learning environment causes learners to engage in cognitive processes that are similar to those in the real world" (p. 322), engaging learners in challenging problems that are often confronted by experts. This view is consistent with the term cognitive fidelity that emphasises the congruence between learned cognitive tasks and the cognitive processes demanded in the real world (Collins, 1996; Menaker et al., 2006). From instructional design perspectives, fidelity means a faithful implementation in which instructional intentions such as the provision of authentic learning contexts are realised. Instructors may find it difficult to fully implement instructional design theories or principles because they have to consider learner's characteristics and instructional environments (Kulo \& Cates, 2013). This leads instructors to apply only part of, or a modified version of, the design theory. However, in the revision process, important elements of the instructional design principle may be missed. (Dusenbury et al., 2003). Even if instructors do not apply all of the design principles, it is important to assess instructional design fidelity.

Flipped learning is an instructional method that emphasises learning experiences that engage learners in cognitive processes demanded in the real-world context. By moving much of the abstract learning outside of class and bringing more practical activities (e.g., problem-solving and discussion) into the class, flipped learning supports learners' active participation and collaborative meaning-making, thereby facilitating knowledge navigation from the abstract to the concrete level $(\mathrm{Ng}, 2014$; Sohrabi \& Iraj, 2016). In a successful flipped learning class, knowledge does not remain disconnected pieces but is integrated to facilitate the transfer to real-life situations.

When the indicators under the four pillars of F-L-I-PTM are fully realised, flipped learning design fidelity was high, and can achieve the intended goal, of helping students become active participants who engage in high-level cognitive processes toward knowledge integration (Branch, 2009). In contrast, low fidelity means that the four pillars are not faithfully integrated into the design of flipped learning; hence, learning experiences are passive, instructor-centered, and distant from what is expected in the real world (CannonBowers \& Bowers, 2008). Figure 1 depicts the spectrum of low and high fidelity of flipped learning design. The outer square represents the ideal situation when the four pillars are fully implemented. "FL Space" refers to the actual class situation where an instructor wants to implement flipped learning. Low fidelity is a situation where an instructor adopts a flipped learning approach but has not fully implemented the four pillars, creating a gap between the ideal situation (outside limits of the square) and the actual class (FL Space). In this case, the level of flipped learning design fidelity is low. On the other hand, when the four pillars are fully implemented in the class, FL Space is close to the square of the ideal situation and the level of flipped learning design fidelity becomes high. It should be noted that while we used a square to indicate the FL Space for easy visualisation, all four pillars may not be implemented equally, leading to different shapes such as a rhomboid or trapezoid shape.

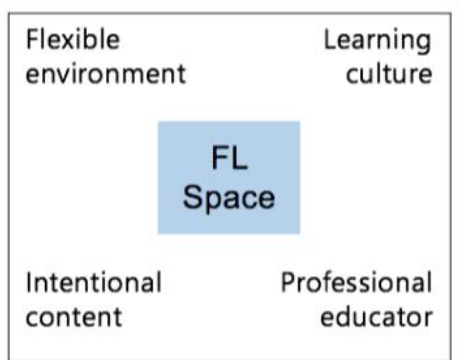

Low fidelity

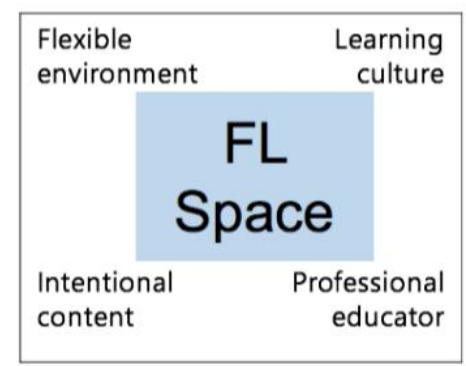

Medium fidelity

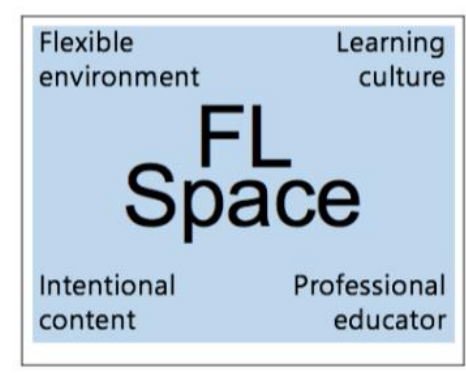

High fidelity

Minimum potential for success

Maximum potential for success

Figure 1. Flipped learning design fidelity (Adapted from Branch, 2009) 


\section{Self-regulation in flipped learning}

While the four pillars of F-L-I-P ${ }^{\mathrm{TM}}$ model emphasise various aspects of learning environments and culture, learner-related factors are neglected to some extent (Chen et al., 2014). The success of flipped learning depends on the instructors' beliefs about its efficacy and appropriate instructional design (Bergmann \& Sams, 2012). Concurrently, the effectiveness of flipped learning may vary depending on the individual learners' efforts (Mason et al., 2013). Therefore, it is necessary to consider not only instructor-related factors but also the learner characteristic of self-regulated learning as a core factor that may determine the success or failure of flipped learning.

In this study, we examined self-regulated learning as an important learner-related factor that influences overall learning outcomes in flipped learning. Pintrich (2000) defined self-regulated learning as "an active, constructive process whereby learners set goals for their learning and then attempt to monitor, regulate, and control their cognition, motivation, and behavior, guided and constrained by their goals and contextual features of the environment" (p.453). In the general context of flipped learning, students need to regulate their learning by viewing short video lectures or other learning materials curated by the instructor as a preclass learning activity. Students in a traditional class focus more on post-class activities than in-class activities. On the contrary, in a flipped learning class, the focus shifts from post-class to pre-class and inclass activities, in order to encourage students' self-regulation and active participation (Long et al., 2016). Thus, the success of flipped learning depends on whether students take responsibility for and regulate their behaviour to complete pre-class activities (Han \& Klein, 2019; Huang \& Hew, 2018; Sun \& Xie, 2020). Previous studies found that some learners do not want to participate in pre-class activities (Chen et al., 2016). For instance, Kim et al. (2014) reported that $25 \%$ of learners in their study attended flipped learning classes without watching video lectures as a pre-class activity.

The empirical study conducted by Sun et al. (2018) supports the important role of self-regulated learning for the students' academic success in the flipped university courses. The results indicate that students' selfefficacy and the use of help-seeking strategies had significantly positive relationships with academic achievement. Similarly, Sletten (2017) found that when learners had a positive attitude toward flipped learning, the level of self-regulated learning increased. van Alten et al. (2020a) examined the effect of selfregulated support in a flipped history classroom on students' learning outcomes. They found that students in the self-regulated learning prompts condition watched more pre-class videos than those in the condition without the self-regulated learning prompts. Also, it has been reported that the goal-setting of self-regulated learning in the MOOCs learning environment has a significant effect on learners' satisfaction and learners' intention-fulfillment (Rabin et al., 2019).

Despite the importance of self-regulation in learning processes and outcomes, even university students tend to have difficulty in developing and possessing proper self-regulatory skills (DiDonato, 2013). Hence, learning environments need to be designed to help learners intentionally and consciously regulate their learning behaviours. An example of such intentional design in a flipped class is reported by Lai and Hwang (2016), who implemented a self-regulated monitoring platform that was designed to support goal-setting and self-evaluation behaviours. To evaluate the effectiveness of this platform, the researchers conducted an experimental design research study in a mathematics class at an elementary school. The researchers found that student performance in the flipped class with the monitoring system was significantly higher than that in the flipped class without the system.

\section{Satisfaction and continuance intention}

Some previous studies that found low student satisfaction with flipped learning, have skeptical views about the efficacy of flipped learning (Hao, 2016; Strayer, 2012). Fisher et al. (2017) found that students had frustration and dissatisfaction with flipped learning. In a flipped learning environment, students have the responsibility to participate in pre-class lectures and to regulate their own learning. However, when students without a routine of class preparation are exposed to the demands of the flipped learning class, they are likely to feel some frustrations and confusion about this new learning approach and may fail to engage in the class. The more learners are familiar with only lecture-centered classes, the more likely they are to reject the flipped learning approach due to the burden of completing pre-class activities (Chen et al., 2016). Nevertheless, there is a lack of research on student satisfaction and their continuance intention to participate in flipped learning classes. 
Among the few existing studies, Kim and Lim (2016) found that the perceived level of self-regulated learning significantly predicted student satisfaction with flipped learning. Abeysekera and Dawson (2015) made several propositions about the flipped classroom from self-determination theory and cognitive load theory. One of their propositions being that the flipped learning environment that encourages active participation and discussions with peers is likely to satisfy students' needs for self-determination (competency, autonomy, and relatedness), which can generate a greater level of intrinsic motivation for learning.

We posit that when learners are satisfied with their flipped learning experiences, they are likely to show an intention to continue participating in other flipped learning courses. Continuance intention has been extensively used in technology acceptance research to understand factors affecting users' continuous use of a certain type of technology in the future (Bhattacherjee, 2001; Davis, 1989). According to the expectationdisconfirmation theory proposed by Oliver (1980), people compare expectations for new technologies with satisfaction of actual use. If there is a discrepancy between expectations and satisfaction, it does not lead to continued use. Based on this, Bhattacherjee (2001) proposed an expectation-confirmation model that shows a causal relationship between satisfaction and continuance intention to use. In the existing research on technology-enhanced learning environments, continuance intention as a construct has been used to measure whether a user (learner) is accepting a new technology or approach beyond the initial satisfaction as well as an indicator of future behaviors. Lin et al. (2016) found a significant relationship between learner satisfaction with blended learning and the continuation intention among university students. Similarly, Joo et al. (2018) confirmed a significant relationship between university students' satisfaction with MOOCs and their persistence intention to take MOOCs.

Thus far, few research studies have examined the continuance intention construct in flipped learning settings. Among the studies available, Lai et al. (2018) investigated university instructors' continuance intention to use flipped learning, based on the theory of self-determination and motivation. They found that instructors' continuance use intention could be predicted by intrinsic challenge motivation (e.g., performing more complex and difficult flipped learning tasks) and extrinsic compensation motivation (e.g., salary, promotion). A study by Mohamed and Lamia (2018) examined the continuance intention to use the flipped classroom from the learner perspectives. Their study showed that perceived usefulness, self-efficacy, compatibility, and perceived support for social ties were significant antecedents to predict student continuance intention to use the flipped classroom. Similarly, Arpaci and Basol (2020) found that perceived usefulness and perceived ease of use had a positive impact on preservice teachers' continuance intention to take flipped learning courses.

Despite its popularity, flipped learning is not considered an evidence-based approach. For example, Abeysekera and Dawson (2015) hold that "[t]he flipped classroom approach is under-evaluated, undertheorised and under-researched in general" (p. 2). Given the research gaps identified in the existing research, this study aimed to provide empirical evidence of the structural relationships between self-regulated learning, flipped learning design fidelity, satisfaction, and continuance intention at a university flipped classroom. Figure 2 shows our hypothetical research model. In this model, flipped learning design fidelity is a design-related factor that intends to measure how learners perceive the degree of learner-centered instructional design aspects in a flipped course, which are measured as the four pillars of F-L-I-PTM. Selfregulation is a learner-related factor that measures how learners self-assess their self-regulated behaviours, such as completing pre-class work, in flipped learning. Next, this research model positions satisfaction and continuance intention as learning outcome variables. Satisfaction is the basic indicator of affective learning outcomes, measuring whether learners perceive positive values in their flipped learning experience. In this study, continuance intention was used to indicate a learner's willingness to complete the current flipped learning course, and to take other flipped learning courses in the future when available. That is, continuance intention includes both the immediate action and future behavioural intention. The following hypotheses are posed:

Hypothesis 1: Flipped learning design fidelity and self-regulated learning will affect student satisfaction in a university flipped learning course.

Hypothesis 2: Flipped learning design fidelity, self-regulated learning, and satisfaction affect student intention to continue participating in a university flipped learning course. 


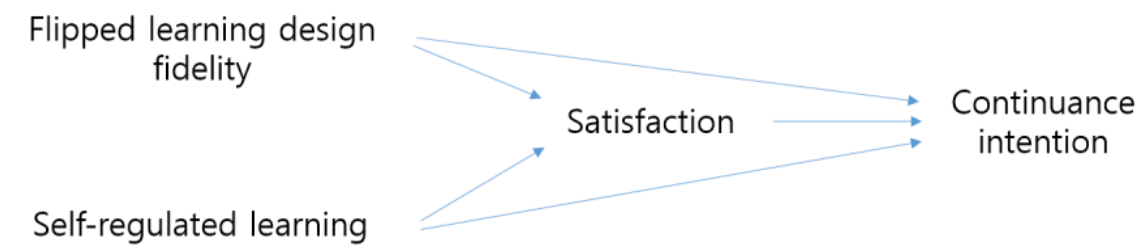

Figure 2. Hypothetical research model

\section{Method}

\section{Research context and participants}

This study was conducted in the 'Introduction to Education' course in a large-sized university in Korea. As one of the foundation courses in the pre-service teacher education program, the course was conducted in a flipped learning mode during the spring semester of 2017, 2 hours per week for 15 weeks. One instructor taught three classes under the same course title, and with the same course syllabus. The participants were recruited by the convenience sampling method. The participants were 140 students enrolled in this course, and the numbers of students in the three classes were 34,39, and 67. After eliminating 6 students due to the incomplete responses, we analysed data from 134 participants. Most students were second-year students (91\%), followed by third-year students $(7.5 \%)$, and final-year students $(1.5 \%)$.

We found this course suitable for examining the issue of flipped learning design fidelity for two reasons. First, the course went through a significant re-design process to include various educational problems in real-world school settings. Previously, the course focused more on covering the basic concepts and theories of various pedagogies and provided little opportunity to engage students in applying their learned knowledge to solving real-world problems that they are likely to face in school. Second, the course also faced the problem with different levels of student prior knowledge. The use of pre-class video lectures helps cognitively prepare students with different knowledge levels to acquire necessary prior knowledge and readiness, thereby reducing the knowledge gap among students (Lee \& Choi, 2019).

Table 2

Course design based on the F-L-I-P $P^{\mathrm{TM}}$ model

Pillars Re-designed components

\begin{tabular}{|c|c|}
\hline Flexible environment & $\begin{array}{l}\text { - Opportunities to experience a variety of learning methods } \\
\text { - (e.g., mini-lectures, learner discussions, presentations, and online } \\
\text { learning) }\end{array}$ \\
\hline Learning culture & $\begin{array}{l}\text { - Weekly group discussions } \\
\text { - } \quad \text { Learners find answers for themselves }\end{array}$ \\
\hline Intentional content & $\begin{array}{l}\text { - Deliver only core content as pre-video lectures } \\
\text { - Suggest in-class discussion topics that incorporate pre-learning } \\
\text { content into real classroom settings }\end{array}$ \\
\hline Professional educator & $\begin{array}{l}\text { - } \quad \text { Prepare weekly lectures and discussions } \\
\text { - } \quad \text { Provide feedback on team activities } \\
\text { - } \quad \text { Provide scaffolding on student discussions }\end{array}$ \\
\hline
\end{tabular}

The instructor stated the basic information about flipped learning in the course syllabus and provided more detailed guidance about flipped learning in the first session. Each week, the instructor provided students with a 10-minute video clip as a pre-class learning activity through the learning management system (Figure 3 ). The lecture videos included core topics, such as educational history, educational philosophy, educational psychology, the sociology of education, and educational curriculum. The face-to-face class was conducted in the form of discussion, in which the instructor provided a list of guiding questions about the core content covered in video clips (e.g., "What factors should be considered when designing teaching and learning activities based on the theory of constructivism?") for the students to discuss in groups. During the first week of the semester, the students formed a group of 4 to 6 members. The instructor also monitored each group's discussion and gave feedback about the areas that groups had difficulties with. After the discussion, the group presented key ideas from their discussion, and $20 \%$ of the total grades were based on their 
participation scores to encourage active participation in class activities. During the last 10 minutes of the class, the instructor consolidated the core ideas and questions, especially discussion topics that required indepth understandings of learning theories.

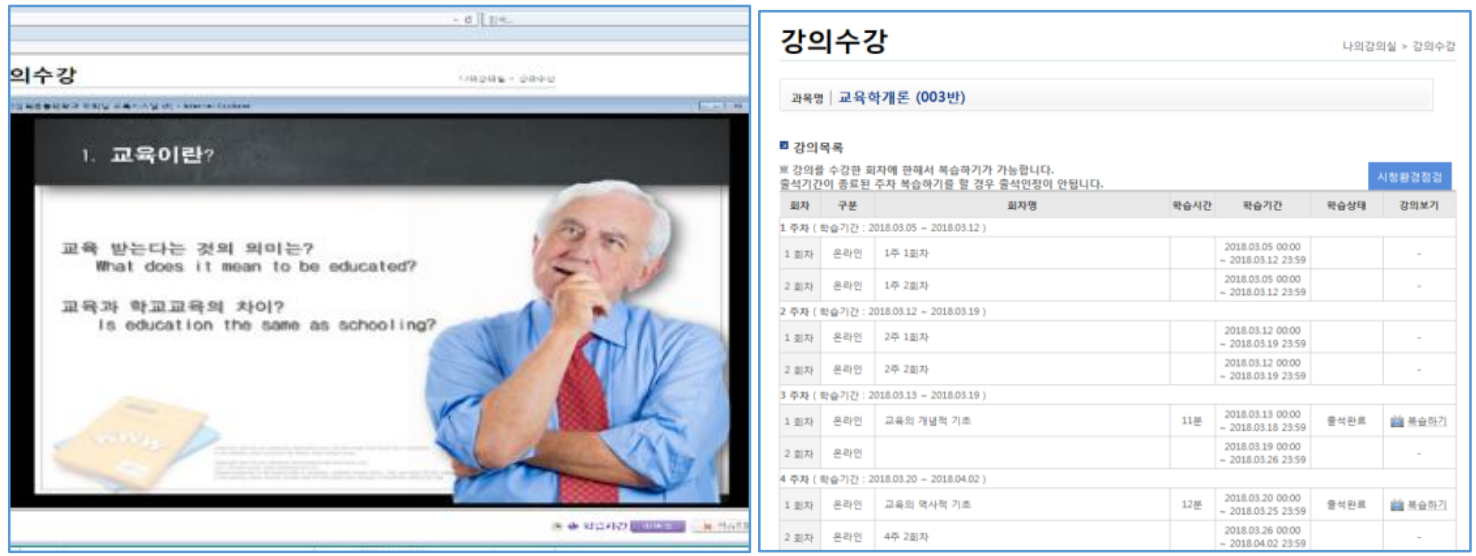

Figure 3. Learning management system: pre-class lecture video (left), monitoring of student progress (right)

\section{Measures}

Relevant existing instruments were selected and modified for the goal and context of this study. We attempted to select instruments that had been validated with Korean samples to minimise any cultural and language variations. Table 3 presents the instrument used with the sample items. The internal validity values measured in Cronbach's $\alpha$ were all above the recommended level, ranging from .879 to .972 . All items were measured using a 5 -point Likert scale $(1=$ strongly disagree, $2=$ agree, $3=$ neutral, $4=$ agree, $5=$ strongly agree). A survey on flipped learning fidelity, self-regulated learning, satisfaction, and continuance intention was distributed at the end of the semester.

First, we used 4 factors with a total of 11 items corresponding to the four pillars of the F-L-I-PTM model (FLN, 2014) in Table 1, to measure whether the class was designed to achieve a high level of fidelity required by the F-L-I-PTM model. The items in each factor were as follows: (a) three items about a flexible environment, (b) two items about learning culture, (c) three items about intentional content, and (d) three items about a professional educator. Since the original items in the model were stated as the indicators that the instructor needed to follow for effective flipped learning (Table 1), we revised them to measure learner perceptions about these indicators.

Second, self-regulated learning was measured by 8 items that correspond to the construct of academic selfregulation in the Motivation Scale for Learners developed by Bong et al. (2012). This instrument measures the cyclical process in which learners plan, check, execute, and reflect to achieve their academic goals (e.g., I evaluate myself to achieve my goals). The tool asks whether learners can use appropriate strategies to achieve a goal, or if they need to modify strategies. The tool has been validated with 514 middle and high school students in Korea. The concurrent validity of this instrument was validated through correlation analysis with the Motivated Strategies for Learning Questionnaire by Pintrich et al. (1991). The reported validity was .76, which was a suitable validity level.

Third, we adapted Shin's (2003) instrument to measure learner satisfaction and learner intention to continue to participate in flipped learning courses. The satisfaction factor consists of 8 items (e.g., The flipped learning method was a valuable experience for me). The continuance intention factor consists of 6 items (e.g., I would like to take a flipped learning course in the next semester). Shin (2003) developed the instrument to measure how students feel about their learning experiences in distance learning environments, and whether, after finishing a certain course or program, students want to continuously learn at their institutions. The validation was done with 111 university students. We modified some statements to ensure that it could be applied to flipped learning environments (e.g., changed a course to a flipped learning course). 
Table 3

Measured variables and sample items

\begin{tabular}{|c|c|c|c|c|}
\hline Variables & $\begin{array}{l}\text { Number } \\
\text { of items }\end{array}$ & Sample items & Source & $\begin{array}{l}\text { Cronbach's } \\
\text { alpha }\end{array}$ \\
\hline $\begin{array}{l}\text { Flipped } \\
\text { learning } \\
\text { design fidelity }\end{array}$ & 11 & $\begin{array}{l}\text { Flexible environment: The } \\
\text { instructor used the classroom time } \\
\text { flexibly, which permitted us to } \\
\text { interact with each other, and to } \\
\text { reflect on what we had learned in } \\
\text { the video in advance. } \\
\text { Learning culture: The instructor } \\
\text { gave students opportunities to } \\
\text { engage in meaningful activities, } \\
\text { without the instructor being } \\
\text { central. } \\
\text { Intentional content: The instructor } \\
\text { prioritised concepts used in direct } \\
\text { instruction, for us to access on our } \\
\text { own. } \\
\text { Professional educator: The } \\
\text { instructor worked to develop better } \\
\text { classes through flipped learning. }\end{array}$ & $\begin{array}{l}\text { Flipped } \\
\text { Learning } \\
\text { Network } \\
(\text { FLN) }(2014)\end{array}$ & .879 \\
\hline $\begin{array}{l}\text { Self-regulated } \\
\text { learning }\end{array}$ & 8 & $\begin{array}{l}\text { I try to figure out what problems I have } \\
\text { in my study. }\end{array}$ & $\begin{array}{l}\text { Bong et al. } \\
(2012)\end{array}$ & .893 \\
\hline Satisfaction & 8 & $\begin{array}{l}\text { The flipped learning method was a } \\
\text { valuable experience for me. }\end{array}$ & Shin (2003) & .972 \\
\hline $\begin{array}{l}\text { Continuance } \\
\text { intention }\end{array}$ & 6 & $\begin{array}{l}\text { I would like to take a flipped learning } \\
\text { class in the next semester. }\end{array}$ & Shin (2003) & .917 \\
\hline
\end{tabular}

\section{Data analysis}

For data analysis, we conducted structural equation modeling (SEM) to investigate the relationships among the variables. The structural model was estimated with the partial least squares (PLS) using Smart PLS. The PLS approach is suitable for research studies with a small sample size (Chin et al., 2003). To apply PLS, the sample size should be greater than 10 times the maximum number of links pointing at any latent variables (Barclay et al., 1995; Chin, 1988), which is often called the 10-times rule. Since there are five links in our research model and the sample size is 134, this study satisfies the 10-times rule. PLS is more appropriate than the covariance-based structural equation method when the research study focuses on prediction or testing a new theory rather than a theory confirmation (Reinartz et al., 2009). We conducted the data analysis in the following steps.

First, we conducted exploratory factor analysis with the collected data. The result confirmed the 1-factor model for the variables self-regulated learning $(\mathrm{KMO}=.883$, Bartlett $=.000$, factor loading from .58 to .80$)$, satisfaction $(\mathrm{KMO}=.920$, Bartlett $=.000$, factor loading from .78 to .90$)$, and continuance intention (KMO $=.861$, Bartlett $=.000$, factor loading from .71 to .92 ). We used item parceling to prevent excessive weighting on the measurement model (Kishton \& Widamn, 1994). Self-regulated learning, satisfaction, and continuance intention were extracted randomly to generate two item parcels, which were used for the structural model. Four item parcels were set for the construct of flipped learning fidelity; as in the F-L-I$\mathrm{P}^{\mathrm{TM}}$ model, this construct is theoretically divided into 4 factors.

Second, we confirmed the reliability and validity of the latent variables to examine how well the observed variables represented the latent variables. Internal reliability is acceptable when the value of composite reliability is 0.7 or higher (Bagozzi \& Yi, 1988). Convergent validity is secured when the value of the average variance extracted (AVE) is above .50 (Fornell \& Larker, 1981; Nunnally \& Bernstein, 1994). When the square root of AVE is larger than the inter-construct correlations, each variable is considered to have discriminant validity (Fornell \& Larker, 1981). 
Third, the validation of the structural model (the inner model in PLS) was conducted to examine relationships among the variables set in this study. To assess the collinearity of the inner model, we checked the variance inflation factor values using SPSS since SmartPLS does not provide these values. In addition, we confirmed $R^{2}$ and the Stone-Geisser's $Q^{2}$ values as predictive power indicators. Finally, we examined the structural path significance using $t$-values calculated in bootstrapping.

\section{Results}

\section{Descriptive statistical analysis}

Table 4 presents the descriptive statistics of the observed variables and inter-construct correlation matrices. We checked the mean, standard deviation, kurtosis, and skewness of each item parcel to confirm the multivariate normal distribution. The normal distribution condition was satisfied because the absolute values of the skewness variables were less than 3, and the absolute value of kurtosis was less than 10 (Kline, 2015).

Table 4

Cross-correlation matrix and descriptive statistics $(n=134)$

\begin{tabular}{|c|c|c|c|c|c|c|c|c|c|c|c|}
\hline Variable & Item Parcel & 1 & 2 & 3 & 4 & 5 & 6 & 7 & 8 & 9 & 10 \\
\hline \multirow{4}{*}{$\begin{array}{l}\text { Flipped } \\
\text { learning design } \\
\text { fidelity }\end{array}$} & $\begin{array}{l}\text { Flexible learning } \\
\text { environment }\end{array}$ & - & & & & & & & & & \\
\hline & Learning culture & $.62 *$ & - & & & & & & & & \\
\hline & $\begin{array}{l}\text { Intentional } \\
\text { content }\end{array}$ & $.68 *$ & $.58 *$ & - & & & & & & & \\
\hline & $\begin{array}{l}\text { Professional } \\
\text { educator }\end{array}$ & $.72 *$ & $.62 *$ & $.64 *$ & - & & & & & & \\
\hline \multirow[t]{2}{*}{$\begin{array}{l}\text { Self-regulated } \\
\text { learning }\end{array}$} & $\begin{array}{l}\text { Self-regulated } \\
\text { learning(1) }\end{array}$ & $.42 *$ & $.46^{*}$ & $.48^{*}$ & $.46^{*}$ & - & & & & & \\
\hline & $\begin{array}{l}\text { Self-regulated } \\
\text { learning (2) }\end{array}$ & $.43 *$ & $.45^{*}$ & $.52 *$ & $.45^{*}$ & $.81^{*}$ & - & & & & \\
\hline \multirow[t]{2}{*}{ Satisfaction } & Satisfaction (1) & $.63^{*}$ & $.61 *$ & $.63^{*}$ & $.63^{*}$ & $.55^{*}$ & $.52 *$ & - & & & \\
\hline & Satisfaction (2) & $.61 *$ & $.62 *$ & $.61 *$ & $.59 *$ & $.57 *$ & $.53^{*}$ & $.95 *$ & - & & \\
\hline \multirow[t]{2}{*}{$\begin{array}{l}\text { Continuance } \\
\text { intention }\end{array}$} & $\begin{array}{l}\text { Continuance } \\
\text { intention (1) }\end{array}$ & $.59 *$ & $.59 *$ & $.54 *$ & $.57 *$ & $.51^{*}$ & $.49 *$ & $.86^{*}$ & $.85^{*}$ & - & \\
\hline & $\begin{array}{l}\text { Continuance } \\
\text { intention (2) }\end{array}$ & $.57 *$ & $.51 *$ & $.56^{*}$ & $.58 *$ & $.62 *$ & $.57^{*}$ & $.83^{*}$ & $.84^{*}$ & $.85 *$ & - \\
\hline \multicolumn{2}{|c|}{ Mean } & 3.98 & 3.96 & 4.05 & 3.95 & 3.55 & 3.59 & 3.73 & 3.73 & 3.67 & 3.72 \\
\hline \multicolumn{2}{|c|}{ Standard deviation } & .61 & .73 & .59 & .62 & .78 & .74 & .84 & .88 & 1.01 & .83 \\
\hline \multicolumn{2}{|c|}{ Skewness } & -.14 & -.45 & -.23 & -.13 & -.52 & -.20 & -.47 & -.49 & -.69 & -.33 \\
\hline \multicolumn{2}{|l|}{ Kurtosis } & -.09 & -.01 & -.14 & -.20 & -.81 & -.44 & -.16 & -.03 & -.06 & -.44 \\
\hline
\end{tabular}

Note. $* p<.05$

\section{Verification of the measurement model}

Prior to conducting SEM, we confirmed the convergent and discriminant validity. The values of AVE ranged from .73 to .97 and the composite reliabilities were greater than .70, indicating sufficient internal reliability and convergent validity. In all cases, the square root of AVE was greater than inter-construct correlation estimates. This confirmed that there was sufficient discriminant validity between the latent variables (Tables 5 and 6$)$. 
Table 5

Convergent validity and reliability of the scales

\begin{tabular}{|c|c|c|c|c|c|}
\hline $\begin{array}{l}\text { Latent } \\
\text { variable }\end{array}$ & Indicators & Loadings & $\begin{array}{c}\text { Cronbach's } \\
\text { alpha }\end{array}$ & $\begin{array}{l}\text { Composite } \\
\text { reliability } \\
(>0.7)\end{array}$ & $\begin{array}{c}\text { AVE } \\
(>0.5)\end{array}$ \\
\hline \multirow{4}{*}{$\begin{array}{l}\text { Flipped } \\
\text { learning } \\
\text { design fidelity }\end{array}$} & Flexible learning environment & .883 & \multirow{4}{*}{.879} & \multirow{4}{*}{0.917} & \multirow{4}{*}{0.734} \\
\hline & Learning culture & .825 & & & \\
\hline & Intentional content & .846 & & & \\
\hline & Professional educator & .872 & & & \\
\hline \multirow{2}{*}{$\begin{array}{l}\text { Self-regulated } \\
\text { learning }\end{array}$} & Self-regulated learning (1) & .954 & \multirow{2}{*}{.893} & \multirow{2}{*}{0.949} & \multirow{2}{*}{0.904} \\
\hline & Self-regulated learning (2) & .947 & & & \\
\hline \multirow{2}{*}{ Satisfaction } & Satisfaction (1) & .987 & \multirow{2}{*}{.972} & \multirow{2}{*}{0.986} & \multirow{2}{*}{0.973} \\
\hline & Satisfaction (2) & .986 & & & \\
\hline \multirow{2}{*}{$\begin{array}{l}\text { Continuance } \\
\text { intention }\end{array}$} & Continuance intention (1) & .961 & \multirow{2}{*}{.917} & \multirow{2}{*}{0.960} & \multirow{2}{*}{0.923} \\
\hline & Continuance intention (2) & .961 & & & \\
\hline
\end{tabular}

Table 6

The square root of AVE for checking discriminant validity

\begin{tabular}{|c|c|c|c|c|}
\hline & 1 & 2 & 3 & 4 \\
\hline 1. Flipped learning design fidelity & $\mathbf{0 . 8 5 7}$ & - & & \\
\hline 2. Self-regulated learning & 0.562 & 0.951 & - & \\
\hline 3. Satisfaction & 0.729 & 0.578 & 0.986 & - \\
\hline 4. Continuance intention & 0.684 & 0.600 & 0.892 & 0.961 \\
\hline
\end{tabular}

Note. Bold text: the square root of AVE

\section{Verification of the structural model}

To evaluate the structural model, we proceed to examine the multi-collinearity between the latent variables. The values of variance inflation factor for all constructs were smaller than the threshold value of 10 (Hair et al., 2009). Second, the Stone-Geisser test criterion $\left(Q^{2}\right)$ exceeded the threshold of 0 for all the endogenous variables, supporting the predictive relevance of the model (Stone, 1974). The results supported the following significant relationships: (a) flipped learning design fidelity has a significantly positive influence on satisfaction $(\beta=.59, \mathrm{t}=8.41, p<.05)$; (b) self-regulated learning has a significantly positive influence on satisfaction $(\beta=.25, \mathrm{t}=3.26, p<.05)$; (c) self-regulated learning has a significantly positive influence on continuance intention $(\beta=.12, \mathrm{t}=2.64, p<.05)$; (d) satisfaction has a significantly positive influence on continuance intention $(\beta=.80, \mathrm{t}=16.53, p<.05)$. However, the relationship between flipped learning design fidelity and continuance intention was not statistically significant $(\beta=.04, \mathrm{t}=.67, p>.05)$.

The significance of the mediating effect was confirmed since both flipped learning design fidelity and selfregulated learning affect satisfaction, and then satisfaction influences continuance intention. Figure 4 shows that: (a) the relationship between flipped learning design fidelity and continuance intention is significantly mediated by satisfaction; (b) the relationship between self-regulated learning and continuance intention is significantly mediated by satisfaction. Table 7 presents the direct and indirect effect of decomposition of the tested relationships in the modified model. 


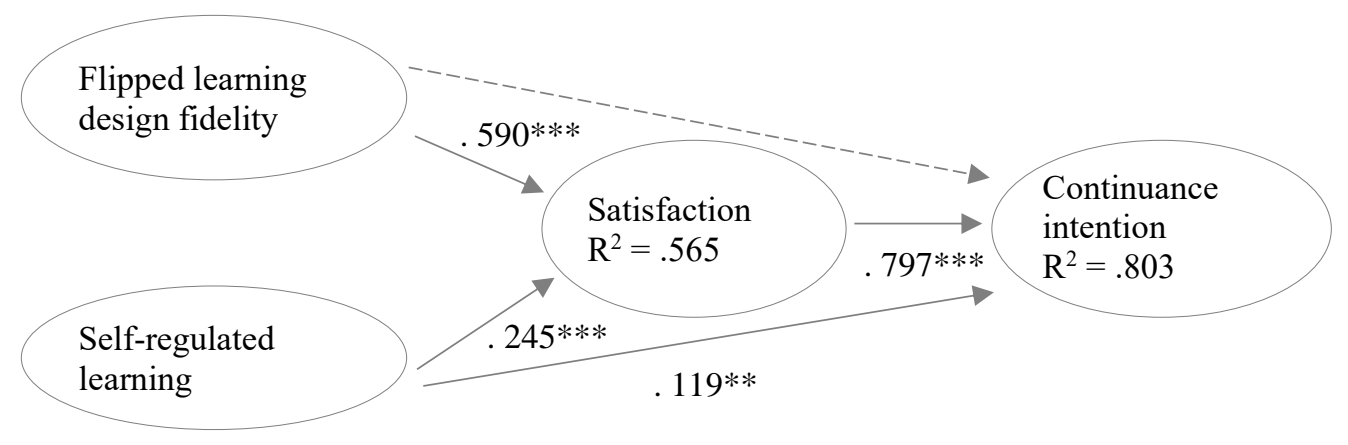

Figure 4. Results of PLS analysis

Note. $* p<.05 ; * * \leq .01 ; * * * \leq .001$

Table 7

Direct and indirect effects $(n=134)$

\begin{tabular}{llcrr} 
& & Total & Direct & \multicolumn{1}{c}{ Indirect } \\
\hline Flipped learning design fidelity & $\rightarrow$ Satisfaction & $.590^{* * *}$ & $.590^{* * *}$ & - \\
\hline Self-regulated learning & $\rightarrow$ & $.245^{* * *}$ & $.245^{* * *}$ & - \\
\hline Flipped learning design fidelity & $\rightarrow$ & $.470^{* * *}$ & .037 & $.470^{* * *}$ \\
\hline Self-regulated learning & $\rightarrow$ Continuance & $.315^{* * *}$ & $.119^{* * *}$ & $.196^{* * *}$ \\
\hline Satisfaction & $\rightarrow$ & $.797^{* * *}$ & $.797^{* * *}$ & -
\end{tabular}

Note. $* p<.05 ; * * \leq .01 ; * * * p \leq .001$

\section{Discussion}

\section{Key findings and implications}

In this section, we revisit the research questions to discuss the key findings and their implications for the design of flipped learning courses in a university context. The first research question examined whether flipped learning design fidelity (design factor) and self-regulated learning (learner factor) affect student satisfaction with flipped learning. The results indicate that both flipped learning design fidelity and selfregulated learning had a significant effect on satisfaction. This finding confirms our position that the reciprocity of self-regulated learning strategies and flipped learning design fidelity is a critical factor for affecting students' expected learning outcomes. This finding is also consistent with the previous studies that found the importance of students' self-regulation in flipped learning (Lai \& Hwang, 2016; Sletten, 2017; Sun et al., 2018).

The second research question examined whether flipped learning design fidelity, self-regulated learning, and satisfaction affect student intention to continue participating in a flipped learning course. Overall, the results indicate that self-regulated learning and satisfaction had a positive influence on continuance intention. Flipped learning provides a context in which learners can demonstrate autonomy, and learners with high self-regulated learning skills are likely to succeed in flipped learning. However, when students have low self-regulation skills, it is easy to have unsatisfactory learning experiences (van Alten et al., 2020b). The relationship between self-regulated learning, satisfaction, and persistence intent obtained from the results of this study supports this argument of previous studies.

The relationship between flipped learning design fidelity and satisfaction revealed in this study supports the claim that well-designed flipped learning opens opportunities for learners to actively participate and can increase learner satisfaction. However, flipped learning design fidelity did not affect directly students' intention to continue participating in a flipped learning course. Instead, flipped learning design fidelity indirectly influences continuance intention through satisfaction. 
The significant relationship between satisfaction and continuance intention has been suggested in the existing online learning research (e.g., Shea et al., 2006; Swan, 2002). To the best of our knowledge, our study is the first attempt to examine the empirical evidence of the relationship between satisfaction and continuance intention in flipped learning settings. However, the non-significant effect of flipped learning design fidelity on continuance intention was an unexpected finding. This study defines flipped learning design fidelity as the degree to which a class is faithfully designed to be close to an ideal flipped learning class operationalised with four indicators in the F-L-I-PTM model. Our finding can be interpreted that a high fidelity of flipped learning design has an impact on immediate outcomes (course satisfaction), but does not necessarily have an impact on distant outcomes (continuance intention). Distant outcomes, such as continuance intention, are influenced by satisfaction and self-regulated learning. This may mean that students who are self-regulatory and find flipped learning experiences satisfactory are likely to continue taking flipped learning courses in the future. This suggests that it is difficult to influence distant outcomes (continuance intention) simply by providing opportunities for participation in flipped learning classes with high design fidelity. Educational institutions and instructors who want to continuously implement flipped learning should seek strategies that can support students' self-regulated learning skills when designing flipped learning classes. In this study, we proved the causal relationship that students are satisfied with flipped learning when flipped learning design fidelity and self-regulated learning capability is enhanced. If students are not satisfied with the flipped learning class, the instructor must find factors that can increase the students' satisfaction in their flipped learning class based on the F-L-I-PTM model elements. In addition to design fidelity, it is also necessary to consider ways to support learners' self-regulated learning and to increase student satisfaction.

Based on the key findings of this study, we can provide some implications for the design of flipped learning courses in university settings. First, to provide learners with satisfactory learning experiences of flipped learning, it is necessary to fully implement each of the four pillars in the F-L-I-PTM model. In Korea, recent studies have shown that university students, having experienced a secondary-school education that mainly focuses on the university entrance examination, could not adapt themselves to participating in studentcentered learning activities in university courses, such as discussion and collaborative work (Jo \& Kim, 2016). For such students, flipped learning methods can be designed to give them gradual autonomy. For example, in the beginning, students can participate in a simple debate individually or in a dyad. In the middle of the semester, they can gradually participate in group discussions and group learning activities. Toward the end of the course, they can engage in complex problem-solving activities.

We propose the following instructional strategies in relation to each of the four pillars in the F-L-I-PTM model. To support flexible learning environments, it is necessary to allow time for students to reflect and elaborate on what they learned from pre-class materials through interaction with other students. During this process, instructors need to provide appropriate scaffolds to students such as specifying reflection topics. Concerning learning culture, instructors need to present meaningful activities in the classroom in connection with the pre-class materials and activities, supporting learner-centered learning culture. In addition to developing pre-class materials, great efforts should be put into designing activities and assignments to be conducted in classrooms. Next, for the intentional content, it is necessary to select the content to be explained through direct instruction and the content to be learned in a self-directed learning mode through pre-class materials. Instructors can adapt existing resources as well as developing new content. As the last pillar, instructors need to grow as experts in flipped learning. The increasing demand for designing and implementing flipped learning courses implies that university instructors need to develop their competency in classroom orchestration. The concept of classroom orchestration is defined as "how a teacher manages, in real time, multi-layered activities in a multi-constraints context" (Dillenbourg, 2013, p. 485). If the instructor teaches a large-sized class, it is challenging to provide specific feedback for each group within a limited time. Under such conditions, it is important to integrate design elements that support classroom orchestration, such as support from teaching assistants and technical tools, making the management of multiple activities more seamless. Therefore, it is necessary to help instructors focus on improving their course's design fidelity.

Third, concerning the importance of self-regulated learning, we suggest that there should be high levels of content relevance and meaningfulness between pre-class learning and in-class learning activities. When students find that what they learn through video lectures in pre-class learning is relevant and meaningful to their learning goals, such a perception is likely to motivate them to complete pre-class activities, and subsequently to be more engaged in in-class discussion and collaborative learning activities. In addition, it 
is important to consider various strategies for monitoring and facilitating the completion of lecture videos before class. For example, a simple quiz can be used to check the level of appropriate prior knowledge among learners. If the level of pre-class learning is not sufficient, then the instructor can summarise key concepts in class, to better cognitively prepare students to participate in follow-up activities. Self-regulation skills should be taught and carefully considered in the design of flipped learning courses. Communicating explicit expectations and requirements for learner autonomy, providing concise learning materials, and providing ways to self-monitor progress (e.g., dashboard) are possible strategies to help students' selfregulation skills to better deal with the demand in flipped learning courses (Cherrez, 2020; Matcha et al., 2019).

\section{Limitations and future research directions}

We suggest the following limitations of this study and the directions for future research. First, it is necessary to further explore various aspects of improving the efficacy of flipped learning. In this study, we examined only the intent to continue as a behavioral indicator and satisfaction as an affective outcome of the learner experiences with flipped learning. In future research, we plan to examine various learning outcomes, such as academic achievement, learning motivation, and intrinsic interest, to better understand factors affecting learner performance in flipped learning environments. Second, this study did not examine the effect of the course instructor. In this study, research was conducted on three classes of the same subject conducted by the same instructor. Therefore, there is a limitation to generalising the research findings because the study did not examine flipped learning classes taught by various instructors. For the success of flipped learning, because the effort, attitude, and efficacy of the instructor are important (Lai et al., 2018), future research can investigate instructor-related variables, such as instructor's beliefs, perceptions, motivation, and perceived challenges. Third, since this study measured self-regulated learning perceived by learners via a survey form, we suggest that future research needs to obtain additional data such as log data from the LMS about actual frequencies and time of participating in pre-class learning activities (e.g., watching video lectures, downloading reading materials) in order to better triangulate data concerning students' selfregulated learning behaviors. Fourth, the generalisation of findings from this study should be limited to similar research contexts and content areas.

The interpterion of continuance intention should be limited to the context where students are given options to choose flipped learning courses over other types of courses. The university where this study was conducted had been promoting the campus-wide initiative for integrating flipped learning approaches in the course design. Hence, students were able to see which course is offered as a flipped learning model when registering for courses. The concept of flipped learning design fidelity can be applied in other areas of university teaching that puts a high emphasis on solving complex problems, linking theory and practices, and authentic learning situations to create learning environments where students are likely to learn knowledge and skills demanded in real-world settings.

\section{Conclusion}

Increasing interest in flipped learning can be found in various settings, such as K-12 education, higher education, teacher education, and military-service training. This study empirically confirmed that learner satisfaction with flipped learning increases when the learner-centered design elements are fully implemented, and such satisfactory experiences also influence learner intention to continue participating in flipped learning courses in the future. Since university students choose what courses to take, flipped learning is unlikely to be adopted widely without students' acceptance and satisfaction. Previous research shows that flipped learning enhances students' high-order thinking skills, problem-solving, teamwork, and collaboration skills (Bond, 2020). It means that continuous participation in flipped learning may help learners develop high-order thinking skills. Therefore, it is important to explore variables that can increase students' satisfaction and their intention to continuously take courses that adopt flipped learning. The main contribution of this study is that it empirically examined both learner-related factors (e.g., self-regulated learning) and design-related factors (e.g., fidelity), and their reciprocal effects on learning outcomes (satisfaction \& continuance intention). For positive learning experiences with flipped learning approaches, this study highlights that instructors need to faithfully implement the core design principles of flipped learning and at the same time incorporate methods to support learners with low self-regulated learning skills. Prior research mainly focused on verifying the effectiveness of treatment by comparing the group that applied strategies to increase self-regulated learning skills in flipped learning with the group that did not 
(van Altan et al., 2020b; Zheng et al., 2020). This study is differentiated in that it investigated the factors that determine which learners experience higher satisfaction among those who participated in flipped learning. Based on the research model proposed in this study, when future studies expand the model that explains the outcome of flipped learning by adding factors that affect learners' self-regulated learning skills, it will provide more sophisticated implications to teaching and learning practices in the university context. Finally, in this study, we proposed the new concept flipped learning design fidelity and emphasised the importance of examining the course design and implementation, beyond simply introducing a new pedagogical approach. We believe that the results of this study can provide empirical evidence and valuable insights into the design and implementation of learner-centered flipped learning courses. In particular, as research on flipped learning continues to accumulate, it is necessary to elaborate on the concept of flipped learning design fidelity by expanding the indicators that can measure the degree of fidelity in subsequent studies.

\section{References}

Abeysekera, L., \& Dawson, P. (2015). Motivation and cognitive load in the flipped classroom: Definition, rationale and a call for research. Higher Education Research and Development, 34(1), 1-14. https://doi.org/10.1080/07294360.2014.934336

Arpaci, I., \& Basol, G. (2020). The impact of preservice teachers' cognitive and technological perceptions on their continuous intention to use flipped classroom. Education and Information Technologies, 25(5), 3503-3514. https://doi.org/10.1007/s10639-020-10104-8

Bagozzi, R. P., \& Yi, Y. (1988). On the evaluation of structural equation models. Journal of the Academy of Marketing Science, 16(1), 74-94. https://doi.org/10.1007/BF02723327

Barclay, D. W., Higgins, C. A., \& Thompson, R. (1995). The partial least squares approach to causal modeling: Personal computer adoption and use as illustration. Technology Studies: Special Issue on Research Methodology, 2(2), 285-324.

Bhattacherjee, A. (2001). Understanding information systems continuance: An expectation-confirmation model. MIS Quarterly, 25(3), 351-370. https://doi.org/10.2307/3250921

Bergmann, J., \& Sams, A. (2012). Flip your classroom: Reach every student in every class every day. International Society for Technology in Education.

Bergmann, J., \& Sams, A. (2014). Flipped learning: Gateway to student engagement. International Society for Technology in Education.

Bond, M. (2020). Facilitating student engagement through the flipped classroom approach in K-12: A systematic review. Computers \& Education, 151. https://doi.org/10.1016/j.compedu.2020.103819

Bong, M. Kim, S. Reeve, J., Lim, H. J., Lee, W. Ahn, H. S., Back, S. H., Cho, C. Chung, Y., Hwang, A., Jiang, Y., Kim, H. J., Kim, J. H., Lee, J., Lee, K. H., Lee, M., Lee, S. K., Lee, S. Y., No, U. K., ... Kim, H. J. (2012). The Student Motivation in the Learning Environment Scales (SMILES). Brain and Motivation Research Institute. http://bmri.korea.ac.kr/english/research/assessment_scales/list.html?id=assessment

Brame, C. (2013). Flipping the classroom. Vanderbilt University Center for Teaching. Retrieved from http://cft.vanderbilt.edu/guides-sub-pages/flipping-the-classroom

Branch, R. M. (2009). Instructional design: The ADDIE approach. Springer.

Brewer, R., \& Movahedazarhouligh, S. (2018). Successful stories and conflicts: A literature review on the effectiveness of flipped learning in higher education. Journal of Computing Assisted Learning, 34(4), 409-416. https://doi.org/10.1111/jcal.12250

Cannon-Bowers, J. A., \& Bowers, C. A. (2008). Synthetic learning environments. In J. M. Spectre, M. D. Merrill, J. van Merrienboer, \& M. P. Driscoll (Eds.), Handbook of research on educational communications and technology (3rd ed., pp. 317-327). Lawrence Erlbaum Associates.

Chen, S. C., Yang, S. J., \& Hsiao, C. C. (2016). Exploring student perceptions, learning outcome and gender differences in a flipped mathematics course. British Journal of Educational Technology, 47(6), 1096-1112. https://doi.org/10.1111/bjet.12278

Chen, Y. L., Wang, Y. P., Kinshuk, \& Chen, N. S. (2014). Is FLIP enough? Or should we use the FLIPPED model instead? Computers \& Education, 79, 16-27. https://doi.org/10.1016/j.compedu.2014.07.004

Cherrez, N. J. (2020). Threading self-regulation and self-efficacy in a flipped college Spanish course. In B. Hokanson, G. Clinton, A. Tawfik, A. Grincewicz, \& M. Schmidt (Eds.), Educational technology beyond content (pp. 165-175). Springer. https://doi.org/10.1007/978-3-030-37254-5_14 
Chin, W. W. (1988). The partial least squares approach for structural equation modeling, In G. A. Marcoulides (Ed.), Modern methods for business research (pp. 1295-1336), Lawrence Erlbaum Associates.

Chin, W. W., Marcolin, B. L., \& Newsted, P. R. (2003). A partial least squares latent variable modeling approach for measuring interaction effects: Results from a Monte Carlo simulation study and an electronic-mail emotion/adoption study. Information systems research, 14(2), 189-217. https://doi.org/10.1287/isre.14.2.189.16018

Collins, A. (1996). Design issues for learning environments. In S. Vosniadou, E. De Corte, R. Glaser, \& H. Mandl (Eds.), International perspectives on the design of technology-supported learning environments (pp. 347-361). Lawrence Erlbaum Associates, Inc.

Davis, F. D. (1989). Perceived usefulness, perceived ease of use, and user acceptance of information technology. MIS Quarterly, 13(3), 319-340. https://doi.org/10.2307/249008

Davis, R. S., Dean, D. L., \& Ball, N. (2013). Flipping the classroom and instructional technology integration in a college-level information systems spreadsheet course. Educational Technology Research \& Development, 61(4), 563-580. https://doi.org/10.1007/s11423-013-9305-6

DiDonato, N. (2013). Effective self-regulation and co-regulation in collaborative learning groups: An analysis of how students regulate problem solving of authentic interdisciplinary tasks. Instructional Science, 41(1), 25-47. https://doi.org/10.1007/s11251-012-9206-9

Dillenbourg, P. (2013). Design for classroom orchestration. Computers \& Education, 69, 485-492. https://doi.org/10.1016/j.compedu.2013.04.013

Dusenbury, L., Brannigan, R., Falco, M., \& Hansen, W. B. (2003). A review of research on fidelity of implementation: Implications for drug abuse prevention in school settings. Health Education Research, 18(2), 237-256. https://doi.org/10.1093/her/18.2.237

Fisher, R., Ross, B., LaFerriere, R., \& Martiz, A. (2017). Flipped learning, flipped satisfaction, getting the balance right. Teaching \& Learning Inquiry, 5(2), 114-127. https://doi.org/10.20343/teachlearninqu.5.2.9

Flipped Learning Network (2014). The four pillars of F-L-I-P ${ }^{\mathrm{TM}}$. https://flippedlearning.org/definition-offlipped-learning/

Fornell, C., \& Larcker, D. F. (1981). Evaluating structural equation models with unobservable variables and measurement error. Journal of Marketing Research, 18(1), 39-50. https://doi.org/10.1177/002224378101800104

Hair, J. F., Black, W. C., Babin, B. J., \& Anderson, R. E. (2009). Multivariate data analysis (7th ed.). Upper Saddle River, NJ: Pearson Education, Inc.

Hamdan, N., McKinght, P., McKinght, K., \& Arfstrom, K. (2013). The flipped learning model: A white paper based on the literature review. Flipped Learning Network. Retrieved from https://flippedlearning.org/wp-content/uploads/2016/07/WhitePaper_FlippedLearning.pdf

Han, E., \& Klein, K. C. (2019). Pre-class learning methods for flipped classrooms. American Journal of Pharmaceutical Education, 83(1), 6922. https://doi.org/10.5688/ajpe6922

Hao, Y. (2016). Exploring undergraduates' perspectives and flipped learning readiness in their flipped classrooms. Computers in Human Behavior, 59, 82-92. https://doi.org/10.1016/j.chb.2016.01.032

Hao, Y., \& Lee, K. S. (2016). Teaching in flipped classrooms: Exploring pre-service teachers' concerns. Computers in Human Behaviors, 57, 250-260. https://doi.org/10.1016/j.chb.2015.12.022

He, W., Holton, A., Farkas, G., \& Warschauer, M. (2016). The effects of flipped instruction on out-ofclass study time, exam performance, and student perceptions. Learning and Instruction, 45, 61-71. https://doi.org/10.1016/j.learninstruc.2016.07.001

Huang, B., \& Hew, K. F. (2018). Implementing a theory-driven gamification model in higher education flipped courses: Effects on out-of-class activity completion and quality of artifacts. Computers \& Education, 125, 254-272. https://doi.org/10.1016/j.compedu.2018.06.018

Hwang, G. J., Lai, C. L., \& Wang, S. Y. (2015). Seamless flipped learning: a mobile technology-enhanced flipped classroom with effective learning strategies. Journal of Computers in Education, 2(4), 449473. https://doi.org/10.1007/s40692-015-0043-0

Jo, K., \& Kim, J. (2016). Tendencies action of college students in flipped learning instruction. Journal of the Korea Entertainment Industry Association, 10(4), 213-214. https://doi.org/10.21184/jkeia.2016.08.10.4.203

Joo, Y. J., So, H. J., \& Kim, N. H. (2018). Examination of relationships among students' selfdetermination, technology acceptance, satisfaction, and continuance intention to use KMOOCs. Computers \& Education, 122, 260-272. https://doi.org/10.1016/j.compedu.2018.01.003 
Kim, M. K., Kim, S. M., Khera, O., \& Getman, J. (2014). The experience of three flipped classrooms in an urban university: an exploration of design principles. The Internet and Higher Education, 22, $37-$ 50. https://doi.org/10.1016/j.iheduc.2014.04.003

Kim, S. W., \& Lim, K. Y. (2016). Relationships among self-regulation, teaching presence, perceived interaction, and learning outcomes in a flipped learning environment: Mediating effects of perceived interaction. The Korean Journal of Educational Methodology Studies, 28(4), 743-766. https://doi.org/10.17927/tkjems.2016.28.4.743

Kishton, J. M., \& Widaman, K. F. (1994). Unidimensional versus domain representative parceling of questionnaire items: an empirical example. Educational and Psychological Measurement, 54(3), 757765. https://doi.org/10.1177/0013164494054003022

Kline, R. B. (2015). Principles and practice of structural equation modeling (4th ed.). Guilford Press.

Kulo, V. A., \& Cates, W. M. (2013). The heart of implementation fidelity: Instructional design and intent. Educational Technology, 53(1), 31-35. https://www.jstor.org/stable/44430114

Lai, C. L., \& Hwang, G. J. (2016). A self-regulated flipped classroom approach to improving students' learning performance in a mathematics course. Computers \& Education, 100, 126-140. https://doi.org/10.1016/j.compedu.2016.05.006

Lai, H. M., Hsiao, Y. L., \& Hsieh, P. J. (2018). The role of motivation, ability, and opportunity in university teachers' continuance use intention for flipped teaching. Computers \& Education, 124, 3750. https://doi.org/10.1016/j.compedu.2018.05.013

Lee, J., \& Choi, H. (2019). Rethinking the flipped learning pre-class: Its influence on the success of flipped learning and related factors. British Journal of Educational Technology, 50(2), 934-945. https://doi.org/10.1111/bjet.12618

Le Roux, I., \& Nagel, L. (2018). Seeking the best blend for deep learning in a flipped classroom-viewing student perceptions through the community of inquiry lens. International Journal of Educational Technology in Higher Education, 15, 1-28. https://doi.org/10.1186/s41239-018-0098-x

Lin, Y. C., Chung, P., Yeh, R. C., \& Chen, Y. C. (2016). An empirical study of college students' learning satisfaction and continuance intention to stick with a blended e-learning environment. International Journal of Emerging Technologies in Learning, 11(2), 63-66. https://doi.org/10.3991/ijet.v11i02.5078

Long, T., Logan, J., \& Waugh, M. (2016). Students' perceptions of the value of using videos as a pre-class learning experience in the flipped classroom. Tech Trends, 60(3), 245-252. https://doi.org/10.1007/s11528-016-0045-4

Mason, G. S., Shuman, T. R., \& Cook, K. E. (2013). Comparing the effectiveness of an inverted classroom to traditional classroom in an upper division engineering course. IEEE Transactions on Education. 56(4), 430-435. https://doi.org/10.1109/TE.2013.2249066

Matcha, W., Uzir, N. A., Gasevic, D., \& Pardo, A. (2019). A systematic review of empirical studies on learning analytics dashboards: A self-regulated learning perspective. IEEE Transactions on Learning Technologies, 13(2), 226-245. https://doi.org/10.1109/TLT.2019.2916802

Menaker, E., Coleman, S., Collins, J., \& Murawski, M. (2006, December, 6). Harnessing experiential learning theory to achieve warfighting excellence. [Paper presentation]. Interservice/Industry Training, Simulation, and Education Conference, Orlando, Florida.

Mohamed, H., \& Lamia, M. (2018). Implementing flipped classroom that used an intelligent tutoring system into learning process. Computers \& Education, 124, 62-76. https://doi.org/10.1016/j.compedu.2018.05.011

$\mathrm{Ng}$, W. (2014). Flipping the science classroom: Exploring merits, issues and pedagogy. Teaching Science, 60(3), 16-27. https://search.informit.com.au/documentSummary;dn=679293416794804;res=IELHSS

Nunnally, J. C., \& Bernstein, I. H. (1994). Psychometric theory (3rd ed.). McGraw-Hill.

O'Flaherty, J., \& Phillips, C. (2015). The use of flipped classrooms in higher education: A scoping review. The Internet and Higher Education, 25, 85-95. https://doi.org/10.1016/j.iheduc.2015.02.002

Oliver, R. L. (1980). A cognitive model of the antecedents and consequences of satisfaction decisions. Journal of Marketing Research, 17(4), 460-469. https://doi.org/10.1177/002224378001700405

Pintrich, P. R., Smith, D. A. F., Garcia, T., \& McKeachie, W. J. (1991). A manual for the use of the Motivated Strategies for Learning Questionnaire (MSLQ). National Center for Research to Improve Post-Secondary Teaching.

Pintirch, P. R. (2000). The role of goal orientation in self-regulated learning. In M. Boekaerts, P. R., Pintrich, \& M. Zeidner (Eds.), Handbook of self-regulation (pp. 451-502). Elsevier Academic Press.

Rabin, E., Kalman, Y. M., \& Kalz, M. (2019). An empirical investigation of the antecedents of learnercentered outcome measures in MOOCs. International Journal of Educational Technology in Higher Education, 16, 1-20. https://doi.org/10.1186/s41239-019-0144-3 
Reinartz, W., Haenlein, M., \& Hensele. J. (2009). An empirical comparison of the efficacy of covariancebased and variance-based SEM. International Journal of Research in Marketing, 26(4), 332-344. https://doi.org/10.1016/j.ijresmar.2009.08.001

Roehl, A., Reddy, S. L., \& Shannon, G. J. (2013). The flipped classroom: An opportunity to engage millennial students through active learning strategies. Journal of Family \& Consumer Sciences, 105(2), 44-49. http://doi.org.ssl.access.ewha.ac.kr/10.14307/JFCS105.2.12

Rudd, J., Stern, K., \& Isensee, S. (1996). Low vs. high-fidelity prototyping debate. Interactions, 3(1), 76 85. https://doi.org/10.1145/223500.223514

Shea, P., Li, C. S., \& Pickett, A. (2006). A study of teaching presence and student sense of learning community in fully online and web-enhanced college courses. The Internet and Higher Education, 9(3), 175-190. https://doi.org/10.1016/j.iheduc.2006.06.005

Shin, N. (2003) Transactional presence as a critical predictor of success in distance learning. Distance Education, 24(1), 69-86. https://doi.org/10.1080/01587910303048

Sletten, S. R. (2017). Investigating flipped learning: Student self-regulated learning, perceptions, and achievement in an introductory biology course. Journal of Science Education \& Technology, 26(3), 347-358. https://doi.org/10.1007/s10956-016-9683-8

Sohrabi, B., \& Iraj, H. (2016). Implementing flipped classroom using digital media: A comparison of two demographically different groups perceptions. Computers in Human Behavior. 60, 514-524. https://doi.org/10.1016/j.chb.2016.02.056

Spector, J. M., Merrill, M. D., Elen, J., \& Bishop, M. J. (Eds.) (2014). Handbook of research on educational communications and technology. Springer.

Stone, M. (1974). Cross-validatory choice and assessment of statistical predictions. Journal of the Royal Statistical Society, 36(2), 111-147. https://doi.org/10.1111/j.2517-6161.1974.tb00994.x

Strayer, J. F. (2012). How learning in an inverted classroom influences cooperation, innovation and task orientation. Learning Environment Research, 15(2), 171-193. https://doi.org/10.1007/s10984-0129108-4

Sun, Z., \& Xie, K. (2020). How do students prepare in the pre-class setting of a flipped undergraduate math course? A latent profile analysis of learning behavior and the impact of achievement goals. The Internet and Higher Education, 46. http://doi.org.ssl.access.ewha.ac.kr/10.1016/j.iheduc.2020.100731

Sun, Z., Xie, K., \& Anderman, L. H. (2018). The role of self-regulated learning in students' success in flipped undergraduate math courses. The Internet and Higher Education, 36, 41-53. https://doi.org/10.1016/j.iheduc.2017.09.003

Swan, K. (2002). Education, building learning communities in online courses: The importance of interaction. Communication \& Information, 2(1), 23-49. https://doi.org/10.1080/1463631022000005016

Tomas, L., Evans, N., Doyle, T., \& Skamp, K. (2019). Are first year students ready for a flipped classroom? A case for a flipped learning continuum. International Journal of Educational Technology in Higher Education, 16(5), 1-22. https://doi.org/10.1186/s41239-019-0135-4

van Alten, D. C., Phielix, C., Janssen, J., \& Kester, L. (2020a). Effects of self-regulated learning prompts in a flipped history classroom. Computers in Human Behavior, 108. https://doi.org/10.1016/j.chb.2020.106318

van Alten, D. C., Phielix, C., Janssen, J., \& Kester, L. (2020b). Self-regulated learning support in flipped learning videos enhances learning outcomes. Computers \& Education, 158. https://doi.org/10.1016/j.compedu.2020.104000

van Merriënboer, J. J., \& Kester, L. (2008). Whole-task models in education. In J. M. Spector, M. D. Merrill, J. van Merrienboer, \& M. P. Driscoll (Eds.). Handbook of research on educational communications and technology (pp. 441-456). Lawrence Erlbaum Associates.

Zheng, B., Ward, A., \& Stanulis, R. (2020). Self-regulated learning in a competency-based and flipped learning environment: learning strategies across achievement levels and years. Medical education online, 25(1). https://doi.org/10.1080/10872981.2019.1686949

Zimmerman, B. J. (1989). A social cognitive of self-regulated academic learning. Journal of Educational Psychology, 81(3), 329-339. https://doi.org/10.1037/0022-0663.81.3.329

Corresponding author: Hyo-Jeong So, Author email hyojeongso@ewha.ac.kr

Copyright: Articles published in the Australasian Journal of Educational Technology (AJET) are 
available under Creative Commons Attribution Non-Commercial No Derivatives Licence (CC BY-NCND 4.0). Authors retain copyright in their work and grant AJET right of first publication under CC BYNC-ND 4.0.

Please cite as: Kim, N. H., So, H. J, \& Joo, Y. J. (2021). Flipped learning design fidelity, self-regulated learning, satisfaction, and continuance intention in a university flipped learning course. Australasian Journal of Educational Technology, 37(4), 1-19. https://doi.org/10.14742/ajet.6046 